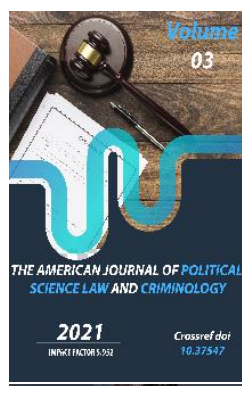

\title{
Analysis Of The Norms Of The Criminal Procedure Code That Use The Term "Procedural Actions": Problem And Solution
}

\section{Kadirov F.F.}

Senior Investigator Of Internal Affairs Bodies Yangikhayat District Of Tashkent City, Uzbekistan

Journal Website: http://usajournalshub.c om/index,php/tajpslc

Copyright: Original content from this work may be used under the terms of the creative commons attributes 4.0 licence.

\section{ABSTRACT}

The article analyzes the norms of the Criminal Procedure Code that use the term "procedural actions", identifies existing problems and shortcomings related to the content of this term. The author developed a definition of the concept of "procedural actions". Proposals and recommendations are given for their reflection in the current Criminal Procedure Code.

\section{KEYWORDS}

Procedural actions, pre-investigation check, inquiries, investigative actions, judicial actions.

\section{INTRODUCTION}

Persons directly and indirectly involved in criminal proceedings, ordinary citizens or employees who apply criminal procedural norms in the course of office work, mainly use the term investigative actions.

Indeed, the stage of pre-trial work is the essence of the criminal procedure. Therefore, 
the actions carried out at this stage are called investigative actions, based on the evidence collected during their implementation, a conclusion is made about the presence or absence of elements of a crime. The terms of investigation and judicial actions, introduced into the Criminal Procedure Code, adopted in 1959, also serve as a basis for it. In particular, Article 1131 of the Criminal Procedure Code defines the time frame for conducting investigative actions, or Article 50 establishes protocols of investigation and court proceedings as a source of evidence, or Article 196 provides for a procedure for appealing against the actions of a prosecutor conducting a preliminary investigation or certain investigative actions. Of course, such an approach of the legislator logically corresponded to the structure of the Criminal Procedure Code and the content of the norms. However, actions related to the stage of the preliminary investigation, as well as actions that can be taken by a defense lawyer, are not regulated by articles of the Criminal Procedure Code.

In other words, while the legislative body focused on the grounds and timing of the initiation of a criminal case, as well as refusal and appeal, it overlooked the scope of actions that must be taken at the stage of initiation of a criminal case and the procedure for their commission. Besides, when determining the procedural status of a defender, no mention is made of the procedure for performing the actions taken by him to protect his client.

Concerning actions related to operationalsearch activities, the introduction of a normative norm was considered completely contrary to the criminal policy pursued at that time. However, the actions mentioned above are among the actions that represent the criminal justice process. An attempt was made to eliminate this obvious flaw in the Criminal Procedure Code of 1994, as a result of which a new term "procedural actions" was introduced into the country's criminal procedural legislation.

On the one hand, this innovation being evaluated positively, first of all, calls on the legislator to regulate the actions to be taken at the stage of initiating a criminal case, the actions of a lawyer related to the defense and actions of operational-search content. Secondly, along with their regulation, he also defined their procedural position. But the term procedural action was introduced into the criminal procedure legislation and, according to E.G. Lukyanova [4], it also caused some problematic situations.

The first problematic situation is the need for clarifying the proportionality between investigative and judicial actions in terms of the content of the procedural actions.

Taking into account the requirements of Article 27 of the Criminal Procedure Code, this article determines the procedure for the legislator to appeal against a procedural action or a decision of an inquiry officer, investigator, prosecutor, judge and court. In turn, if we talk about Article 150 of the Criminal Procedure Code concerning procedural actions related to the exhumation of a corpse, including attempts to examine the corpse, identify it and take samples for examination. Thus, the legislature, while offering a broader understanding of procedural actions, emphasized that investigative actions are also expressed by their procedural nature. 
Yu.S. Vashchenko describes procedural actions in legislation and uncertainty of similar terms as "an abstract place". Taking into account that laws are used not only by courts or government officials, but also by citizens, he proposes not to use abstract terms and rules and that they should be approached in terms of "factual accuracy" and "appropriate clarity" [1].

Consequently, when it comes to procedural, investigative and judicial actions, it would not be very correct to assume proportionality between them. Because it becomes clear that the actions taken before and during the trial are external and internal. By their appearance, the actions taken during the pre-investigation check can be called the actions of the preinvestigation check, the actions taken during the inquiry can be called the actions of the inquiry, the actions taken during the preliminary investigation can be called the investigative actions, the actions taken in the trial, called judicial actions, but it is difficult to immediately determine to which process these procedural actions belong.

According to the legislator, procedural actions are a manifestation of all external actions that are performed before the investigation, preliminary investigation and trial. This can be seen in the amendments and additions made to the Criminal Procedure Code in recent years. In particular, according to part 4 of Article 392 of the Criminal Procedure Code, an official of a body conducting a pre-investigation check or operational-search activity is entrusted with the implementation of certain procedural actions and operational-search activities in the case and assist the investigator, inquirer in the performance of procedural actions.
Part 5 of the norm provides that the official of the body conducting the pre-investigation check, when performing the pre-investigation check, as well as when executing the instructions of the investigator, must perform procedural actions and make decisions under the rules established by this Code.

Section 4 of Article 91 emphasizes that a survey of the place of an incident, a search, verification of evidence at the place, an investigative experiment is a procedural action. However, Articles 911-914 provide for the conduction of investigative actions through a videoconference, and not procedural actions. The analysis of the norms of the Criminal Procedure Code gives grounds to conclude that the legislator used the term "investigative action" only if he intended to emphasize that this action is provided for in part 1 of Article 87 of the Criminal Procedure Code.

If to proceed from the internal form of procedural, investigative and judicial actions, then we can notice that the actions regulated by the articles of the Criminal Procedure Code have the same internal order in content, that is, the grounds and order of their commission are the same. Usually, they differ from each other in the subject of their commission and some design features. More precisely, if the investigator decides to commit certain procedural actions, then the court is satisfied only by making a decision. This shows that procedural actions are not the object of determining the proportionality of investigative and judicial actions from the point of view of external and internal appearance. Because, investigative and judicial actions differ not in content, but the stage of their implementation. 
The second problematic situation. Preinvestigation check, actions performed during the trial, inquest, preliminary investigation, trial or procedural actions carried out with the aim of quickly and completely detecting crimes, punishing a certain person who committed a crime, as well as refusing to punish and convict an innocent person, disclosing the guilty are not cases that attract the attention of the practitioner. Maybe that's why B.Kh. Pulatov understands that investigative actions are also carried out during the judicial investigation [7].

According to the content of Part 1 of Article 87 of the Criminal Procedure Code, actions taken during the preliminary investigation are called investigative actions, and actions taken during the trial are called judicial actions. However, the pre-trial stage is not limited to the preliminary investigation, but also includes a pre-investigation check and stages of inquiry. If the legislator, according to the Criminal Procedure Code of 1959, based on the abovementioned logic, names the actions to be taken during the inquiry as actions of inquiry (in particular, paragraph 3 of Article 100 of the Criminal Procedure Code states, "after the inquiry officer considers that the investigation has been completed ..." or paragraph 2 of Article 105 states that "inquest in cases in which a preliminary investigation is not mandatory must end with the formation of an indictment and the termination of the case"), then the actions were taken at the preliminary investigation stage should logically be called a preliminary investigation. However, in part 2 of Article 329 of the current Criminal Procedure Code, it is noted that the legislative body, recognizing the actions taken before the initiation of the case, thereby prohibited the conduct of other investigative actions.
The texts of these articles were formed based on the amendments and additions to the Criminal Procedure Code in different periods, as a result of which the logic of assigning names to procedural actions performed at different stages of criminal proceedings was violated. Besides, the text cites the concept of investigative actions as a generalizing concept of procedural actions, requiring that investigative actions be given the status of procedural actions and that the same situation becomes one of the factors causing the aforementioned problem situations.

It is known that judicial actions are carried out based on the principles of investigating criminal cases in a collegial and individual manner, the openness of criminal cases in court, public participation in the consideration of criminal cases, direct and oral examination of evidence, as well as there is no need to draw up a separate protocol for each action taken.

If based on this logic of the legislative body, we understand investigative and judicial actions from the point of view of content as separate actions, then it is not clear that the composition of both actions constitutes the same system of actions.

In fact, since these are different actions, they must also consist of a certain system of actions. This once again confirms our conclusion that the above investigative and judicial actions differ not in their internal structure, but their appearance.

However, according to I.L. Petrukhin, the investigation and all other procedural actions can be carried out only after the initiation of a criminal case. In particular, coercive measures of the criminal procedure (search, seizure of postal telegrams) cannot be applied before the 
initiation of a criminal case. But, the initiation of a criminal case is based on the actions taken before the initiation of a criminal case, and, therefore, this stage is considered the stage of pre-investigation verification.

As a rule, the necessary, and in some cases sufficient materials are collected at the stage of pre-investigation verification [5; (A. Panyukov also expressed his opinion on this issue)]. According to the scientist, these materials have a non-procedural form and only after the initiation of a criminal case and subsequent procedural actions, as a result, they acquire a procedural form. Perhaps, on this basis, the current practice has turned the pre-investigation check into a non-procedural form of inquiry and preliminary investigation [6].

A.N. Khalikov, who researched to optimize the pre-trial process, drew attention to the receipt of information that has no evidentiary value during the pre-trial investigation to determine the quality and dynamics of evidence collected during the pre-trial stage. In his opinion, if today's criminal procedure legislation leaves the stage of initiating a criminal case without supervision, then the actions that must be taken before the initiation of a criminal case (search, seizure, exhumation, etc.) will be limited to certain procedural actions necessary for search for the culprit and proof of his guilt. This situation not only impedes the timely disclosure of the crime, the identification of the perpetrator and the proof of his guilt, but leads to some gross violations, that is, the rejection or initiation of an unfounded criminal case [10].

Besides, this leads to a gross violation of the rules regarding the stage of initiation of a criminal case to comply with the provisions of the criminal procedure legislation, in particular, the timing of the pre-investigation check. The reason is that the scope of the procedural actions that can be performed at the stage of initiating a criminal case is limited, and the content of the preliminary investigation consists of the examination and verification of documents, as well as operational-search measures carried out by a specialist. This makes it urgent to enhance the capabilities of the stage of initiating a criminal case. It should also be noted that the legislation of many foreign countries does not provide for the stages of initiating a criminal case at all, and therefore the officials conducting the preinvestigation check begin to collect evidentiary information as soon as they receive information about the crime (Austria, Germany, the United States and others).

Indeed, it is difficult to recognize the stage of the preliminary investigation as a separate stage, similar to the stage of preliminary investigation in terms of its procedural status. Because, although the scope of procedural actions at this stage is limited, according to the observations of the experts interviewed, almost all the investigative actions listed in Article 87 of the Criminal Procedure Code are carried out at the stage of initiating a criminal case.

It can be seen that the legislative body defined the stage of initiating a criminal case as a separate stage, but did not regulate the collection of documents collected at this stage, in particular, the request for additional documents and comments, detention, an inspection of the scene based on their procedural status. This can be seen from the fact that the examination carried out during the preliminary investigation, inspection of the place of the incident, the rules for conducting 
investigative actions were applied at the stage of initiating a criminal case, as well as you can also see this when a case arises of the need to collect, study and cover the process of assessing evidence.

Although the requirements of the Criminal Procedure Code provide for a request for additional documents and comments in terms of the procedural form, the conditions, sequence and procedure for their implementation are not described in detail in the code. Naturally, the inclusion of actions that do not have a procedural form in the list of procedural actions casts doubt on the recognition of information obtained as a result of their transmission as evidence.

A similar situation can be traced to the existence of problems with the determination of the procedural status of a defender in the criminal procedure legislation. Article 53 of the Criminal Procedure Code provides that the defense lawyer is a participant in the proof process and must take certain actions to protect his client, which can be initiated by the defense lawyer, but the scope of these actions is limited to interrogation, obtaining written explanations, characteristics and other documents.

From this point of view, the legislative body provides that these actions can be performed by the defense attorney, emphasizing that the adversarial principle can be applied during preinvestigation, inquiry and preliminary investigation, but the conditions, sequence and procedural order of such actions are not regulated by other articles of the Criminal Procedure Code. This leads to several problematic assumptions.
Firstly, the interrogation of the defense, obtaining a written explanation and a request for a certificate, characterization and other documents include such actions as interrogation, arrest, consideration and presentation provided for by the Criminal Procedure Code.

Secondly, the defense attorney cannot conduct a "defense lawyer's investigation" simultaneously with the right to interrogate, receive a written explanation and send a request for a certificate, characterization and other documents. Because the procedural form of the interrogation, the written explanatory note and the request of the defense attorney for a certificate, characterization and other documents are not defined in the Criminal Procedure Code. And here the question arises, do the documents that are requested on the initiative of the defense attorney and presented to the inquiry officer and the investigator serve as evidence?

According to S.A. Shafer, all certificates, characteristics and other documents related to the investigation of a criminal case have a procedural form, since they are carried out within the framework of the law, and the evidence obtained as a result of their transfer must be included in the criminal case as evidence [11]. However, M.S. Strogovich and I.L. Petrukhin believe that evidence can be considered as evidence only when it is formalized in a procedural order [7; 9].

According to procedural scholars, actions taken in the course of criminal proceedings can be procedural or non-procedural, depending on the procedural formalities, as well as on the probative value of the materials collected as a result of the actions, and on whether the actions were committed by persons with 
procedural powers. Such an artificial classification, which is not justified from the point of view of criminal procedure law, hinders the performance of the functions of criminal procedure legislation. Since, in their opinion, the data collected as a result of "nonprocedural", [2; 3] actions are not eligible for inclusion in the evidence base. The most dangerous aspect of this situation is that the activities of the defense and operationalsearch bodies in the criminal court process are declared non-procedural and lead to their exclusion from the scope of the procedural process. However, part 1 of Article 87 of the Criminal Procedure Code notes that evidence is collected not only during the investigation and trial, but also as a result of operational-search activities.

It is interesting that, even though the term procedural actions are reflected in the norms of the Criminal Procedure Code, procedural actions in the literature still imply investigative actions.

Most scholars interpret investigative actions in a broad sense, including almost all of the investigator's procedural actions, the procedural decisions he or she makes, and even organizational support and law enforcement processes. Although the purpose of these actions is not to collect and consolidate evidence, but to ensure the rights of the participants in the process, to provide the necessary conditions during the investigation (for example, to announce the defendant about the completion of the preliminary investigation and explain to him/her the right to familiarize himself with the case materials), since a preliminary investigation has been carried out, they should also be called investigative actions. Of course, they are not included in the list of actions that have evidentiary value, but their implementation ensures the conduction of a criminal case at the stage of pre-trial investigation. Therefore, they can be included in the list of supporting or auxiliary activities.

If to take into account that the pre-trial stage of the case, in addition to the stage of the preliminary investigation, consists of the stages of pre-investigation verification, initiation of a criminal case and inquiry, in this case, the actions taken during the preliminary investigation do not cover the pre-trial stages in terms of internal and external forms of actions. And this defines the "procedural action" reflected in the current Criminal Procedure Code, which does not depend on the actions taken at the stage of pre-trial investigation, but covers all types (based on evidence, confirming) actions that represent the content of pre-investigation check, operational search, inquiry, preliminary investigation and judicial activity, defines the concept of "procedural actions", reflected in the current Criminal Procedure Code in the following context and justifies the expediency of its use as a single criterion: "Procedural action is a pre-investigation check, operational-search activity, as well as inquiry, preliminary investigation and judicial proceedings by an inquiry officer, an investigator, a prosecutor, a court (judge) and a defense lawyer in pre-trial proceedings and court proceedings, provided for by the norms of criminal procedure law, which is an appropriate procedural action, as well as an additional document that has fact technical value or supporting recommendation that is used during the trial". 
In conclusion, it can be noted that the recognition of the above definition in a separate article in the first paragraph of the general part of the Criminal Procedure Code limits the procedural and non-procedural nature of the activities of the inquiry officer, investigator, prosecutor, court (judge) and defense lawyer.

\section{REFERENCES}

1. Vashchenko Yu.S. On the communicative accuracy of the legislative text in lawmaking // Russian Justice. - M., 2006. No. 4. - P. 58.

2. Criminal Procedure B.A. Edited by Mirensky. - T., 2004. - P. 218.

3. Criminology II (Textbook for university students). Under the general editorship of G.A. Abdumajdov. "Adolat" - T., 2003. - P. 21.

4. Lukyanova E.G. Trends in the development of procedural legislation in the light of the general theory and law // State and Law. - M., 2003. No. 2. - P. 105.

5. Panyukov A. Procedural activity without initiating a criminal case // Russian Justice. - 2003. No. 5, - P. 51-53.

6. Petrukhin I.L. Initiation of a criminal case under the current Code of Criminal Procedure // State and Law. - 2005. No.1. - P. 64.

7. Petrukhin I.L. Theoretical foundations of the reform of the criminal process in Russia. - M., 2004. - P. 14;

8. Pulatov B.H. Importance and prospects of judicial and legal reforms in Uzbekistan // Judicial and legal reforms in the Republic of Uzbekistan: current status, problems and solutions / Republican scientific-practical conference. Tashkent, "Academy" 2008. - P. 40-44.

9. Strogovich M.S. The course of the Soviet criminal process. - T.1, - M., 1968. P. 302.

10. Halikov A.N. Issues of pre-trial proceedings // Russian Justice.

- M., 2008. - No. 9, - P. 50.

11. Sheifer S.A. Where is the Russian court proceeding? (reflections on the vectors of development of criminal procedure legislation // State and Law. ? M., 2005. - No.1. - P. 67. 